\title{
Fitness Cost and Compensation Mechanism of Sulfonamide Resistance Genes (Sul1, Sul2, and Sul3) in Escherichia Coli
}

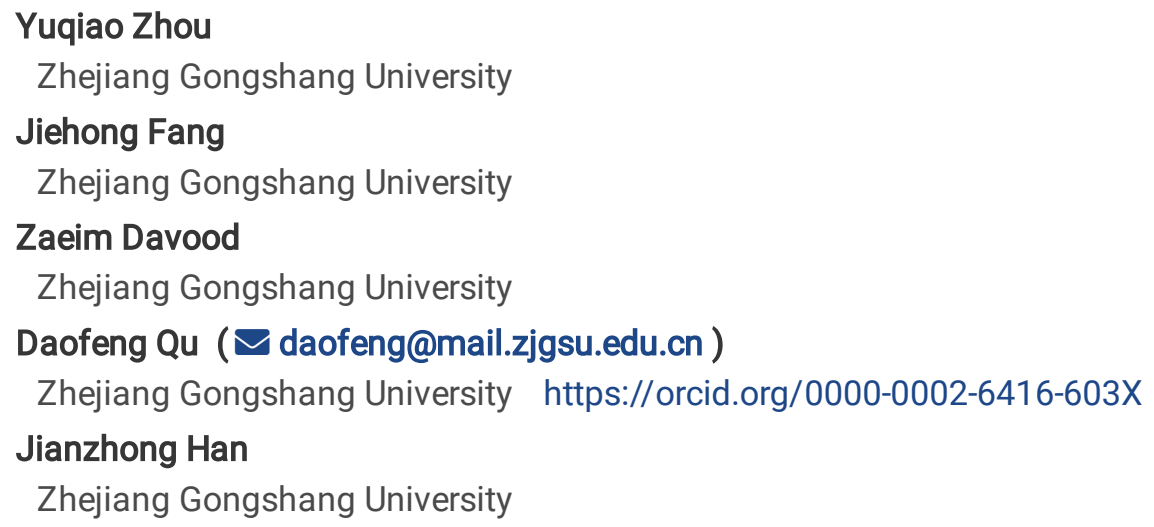

Yuqiao Zhou

Zhejiang Gongshang University

Jiehong Fang

Zhejiang Gongshang University

Zaeim Davood

Zhejiang Gongshang University

Daofeng Qu ( $\sim$ daofeng@mail.zjgsu.edu.cn )

Zhejiang Gongshang University https://orcid.org/0000-0002-6416-603X

Jianzhong Han

Zhejiang Gongshang University

\section{Research}

Keywords: sul genes, fitness cost, Escherichia coli, differentially expressed protein, qRT-PCR

Posted Date: May 21st, 2021

DOI: https://doi.org/10.21203/rs.3.rs-504582/v1

License: () (i) This work is licensed under a Creative Commons Attribution 4.0 International License. Read Full License

Version of Record: A version of this preprint was published at Environmental Microbiology on October 12th, 2021. See the published version at https://doi.org/10.1111/1462-2920.15783. 


\section{Abstract}

Background: The fitness cost of antibiotic resistance is a crucial factor to determine the evolutionary success of resistant bacteria. Even if the selection pressure in the environment is eliminated, drug-resistant bacteria can still compensate for drugresistant genes' fitness cost through some compensation mechanisms. The fitness cost and compensatory evolution of antibiotic resistance are an essential part of bacterial evolution.

Result: Engineered bacteria with the same genetic background that carry sulfonamide resistance gene were generated to explore the fitness cost of sulfonamide resistance gene in Escherichia coli. There were significant differences in the protein expression of the two-component system pathway (fliZ, fliA, fliC and IrhA), folate biosynthesis pathway (sul1, sul2 and sul3), $A B C$ transporter system (ugpC, rbsA and gsiA), and outer membrane pore protein OmpD through the comparative analysis of differential proteins compared to sensitive bacteria. Thus, we could speculate the possible fitness compensation mechanism. Finally, qRT-PCR was used to verify the functions of some differential proteins at the transcriptional level.

Conclusions: The study of fitness cost assessment and compensatory evolution of bacterial resistance will help understand the development track of antibiotic resistance of bacterial pathogens and provide new ideas for solving antibiotic resistance issues.

\section{Introduction}

The spread of MDR (multidrug-resistant) amongst Gram-negative bacteria has emerged as one of the most pressing global public health threats [1]. As synthetic broad-spectrum antimicrobial agents, sulfonamides have inhibitory activity against most $\mathrm{G}^{+}$and $\mathrm{G}^{-}$bacteria [2]. While sulfonamides play a substantial role in preventing and treating animal bacterial diseases, bacteria have developed extensive and robust resistance to them [3]. Bacteria usually produce resistance to sulfonamides through two different strategies: (i) gene mutation and (ii) gene substitution. In gene mutation, the gene fo/P of dihydrosphenoic acid synthase (DHPS), located on the chromosome, produces drug resistance [4]. In gene substitution, drug resistance is generated by obtaining DHPS replacement genes sul1, sul2 and sul3. The expression products of the latter mechanism have a lower affinity for sulfonamides [5]. The second mechanism of sulfonamides resistance is more widespread [6].

Several recent reports have shown that sul gene is found and prevalent in Escherichia coli from human and livestock origins, and it may have stable vertical and horizontal transmissions [6].The base sequences of sul1, sul2, and sul 3 have about $50 \%$ homology with each other [7]. The primary mechanism of drug-resistant gene transmission is the horizontal or vertical transfer of mobile genetic elements carrying drug-resistant genes [8]. Gene su/ has been identified on both chromosomes and plasmids. At present, plasmids, integrons, transposons and other mobile gene elements (MGEs) have been found to be related to the transmission of sulfonamides resistance [9].

The sul gene originated from animal-associated bacteria. It has been frequently isolated from livestock and is supposedly sustained by sulfonamide's heavy usage in the veterinary sectors $[10,11]$. The genes sul 1 and sul 2 were first published by Swedbery and Radstrom, respectively, in 1983 and 1985. Sul2 was more common and widely distributed in clinical Escherichia colithan the gene sul1 [12]. The sul1 gene is mainly associated with other resistance genes on the integron retention fragment [13]. The sul2 gene is often associated with streptomycin resistance genes found in small, unbound plasmids with a broad host range [14]. In 1990, Martin CT found a gene similar to sul1 in Mycobacterium, but the gene had missed the promoter codon, and the codon had been inserted further upstream, so the gene was named sul3 gene [15]. China has a vast territory with numerous pig farms, making the detection range of sulfonamides in pig faeces samples difficult. Furthermore, the highest detection concentration can reach $50 \mathrm{mg} / \mathrm{kg}$ [16-18].

The development of antibiotic resistance often comes with a fitness cost, defined by reduced competitive ability in an antibioticfree environment. This phenomenon usually allows the fitter, often susceptible strain to outcompete the resistant one [19]. Given the biological basis of transmission and epidemic, the fitness cost and compensation mechanism of sul gene in $E$. coli have not been reported. 
The present study aims to investigate the fitness cost of sulfonamide resistance genes in E. coli. bacterial competition in vitro test was used to assess the fitness cost of sul genes in $E$. coli. The label-free proteomics and real-time fluorescent quantitative PCR were applied to explore adaptive changes of sul gene in E. coli strains at different protein expression levels. This study may help to explain the possible adaptive mechanism of these genes, which provides theoretical support to control their transfer and spread.

\section{Methods}

\section{Bacterial strain and plasmids}

E. coli $\mathrm{DH} 5 \mathrm{a}$ and E. coli BL21 were used as the clone and the expression strains respectively. The sulfonamide resistant genes sul1, sul2 and sul3 were inserted into polyclonal sites of the constitutive expression plasmid pET23a (Novagen, USA) using BamH I and Sac I enzymes through the gene recombination method. Recombinant plasmids pET23a-sul1, pET23a-sul2 and pET23a-sul3 carrying sulfonamide resistance genes were transformed into $E$. coli BL21 cells by heat shock transformation method. Single colonies of the transformed plasmids were selected and inoculated into LB liquid medium and incubated at $37^{\circ} \mathrm{C}$ and $200 \mathrm{rpm}$ for $5 \mathrm{~h}$. General primers of the vector T7 promoter and terminator were used for colony PCR identification.

\section{Antimicrobial susceptibility test}

MICs were determined by broth dilution method with an inoculum of $10^{5} \mathrm{CFU} \mathrm{ml}^{-1}$ in LB medium. Each test was repeated three times at least.

\section{Plasmid stability and growth kinetics}

Transconjugants E. coli BL21: pET23a-sul1, E. coli BL21: pET23a-sul2 and E. coli BL21, pET23a-sul3 and E. coli BL21: pET23a were propagated by serial transfer for 14 days of passage. The culture broths were serially diluted in $0.9 \%$ saline and plated onto LB agar without sulfonamide. Approximately 100 colonies were randomly chosen and replica plated onto sulfonamidecontaining and antibiotic-free LB agar plates. The percentage of plasmid retention was calculated by dividing the number of colonies on sulfonamide-containing LB agar by the total number of colonies patched. Three biological replicates were included for each group. The growth kinetics of E. coli BL21 and its transformants carrying the plasmids pET23a-sul1, pET23a-sul2, pET23a-sul3 and pET23a were studied by inoculation in $150 \mathrm{~mL}$ of fresh LB broth. The initial optical density at $600 \mathrm{~nm}\left(\mathrm{OD}_{600}\right)$ was 0.6 , and the bacterial growth was monitored by hourly recording $\mathrm{OD}_{600}$ for $24 \mathrm{~h}$ at $37^{\circ} \mathrm{C}$. Experiments were performed in triplicate.

\section{Motility test}

Engineered bacteria and control strains were inoculated into $\mathrm{MH}$ liquid medium. When the initial $\mathrm{OD}_{600}$ value was $0.3,5 \mu \mathrm{L}$ aliquot of bacterial suspension was taken and inoculated into the center of a $0.4 \% \mathrm{MH}$ agar medium plate $(\varnothing=9 \mathrm{~cm})$ and incubated at $37^{\circ} \mathrm{C}$ for $48 \mathrm{~h}$.

\section{In vitro competition experiments}

To assess the fitness effect of sul1, sul2, sul3 in the bacterial host, E. coli BL21: pET23a-sul1, E. coli BL21: pET23a-sul2 and E. coli BL21 pET23a-sul3 were used to compete against E. coli BL21: pET23a. E. coli BL21: pET23a was mixed with the control strain in the ratio of $1: 1$ by volume. The bacterial suspension was transferred to fresh LB medium at a volume ratio of 1:100 every $24 \mathrm{~h}$ for 5-6 times. Before each transfer, the mixed bacterial suspension was plated on the non-resistant LB medium to calculate the total number of colonies. 100 single colonies were picked from the non-resistant plate and inoculated on the LB 
resistant plate (4 mg/ $\mathrm{mL}$ sulfamethoxazole concentration). The number of sulfamethoxazole resistant colonies was calculated by Eg. 1.

Eq. $1 . \quad$ Selection coefficient $=[\ln (E / R) t-\ln (E / R) 0] / T$

In which, $\mathrm{E}$ is experimental group cell number, $\mathrm{R}$ is control group cell number, and $\mathrm{T}$ is passage number.

\section{Preparation and quantitative analysis of proteome samples}

The engineered and control strains were cultured for $7 \mathrm{~h}$ to the logarithmic growth phase. Bacterial suspensions were centrifuged at $5000 \times g$ and $4{ }^{\circ} \mathrm{C}$ for $10 \mathrm{~min}$. After decanting the supernatant, cells were thoroughly washed twice by the addition of PBS and subsequent centrifugation under the same condition. Each sample added a moderate amount of SDT lysis buffer (SDS, dithiothreitol, Tris) for $60 \mathrm{~s}$. The sample was then ultrasonized for $10 \mathrm{~s}$ at each interval of $15 \mathrm{~s}$ for 10 cycles. After $15 \mathrm{~min}$ in boiling water bath, the sample was centrifuged at $14000 \times g$ for $40 \mathrm{~min}$. After centrifugation, the supernatant of each sample was quantified with BCA kit and analysed by SDS-PAGE.

\section{Enzymatic hydrolysis of proteins}

A 30- $\mu \mathrm{L}$ aliquot of protein solution was taken from each sample, DTT was added to the final concentration of $100 \mathrm{mM}$, boiled in water for $5 \mathrm{~min}$. Two hundred $\mu \mathrm{L}$ UA Buffer was added and mixed well, then transferred into a $10 \mathrm{kD}$ ultrafiltration tube and centrifuged at $14000 \times g$ for $15 \mathrm{~min}$. One hundred $\mu \mathrm{L}$ IAA buffer (100 mM IAA in UA) was added, followed by $600 \times g$ oscillation for $60 \mathrm{~s}$. The dark reaction was carried out for $30 \mathrm{~min}$ followed by centrifugation at $14000 \times g$ for $15 \mathrm{~min}$. Subsequently, $100 \mu \mathrm{L}$ UA buffer was added and centrifuged at $14000 \times g$ for 15 min, repeated twice. One hundred $\mu \mathrm{L} \mathrm{NH}_{4} \mathrm{HCO}_{3}$ solution $25 \mathrm{mM}$ was added and centrifuged at $14000 \times g$ for 15 min, repeated twice. Forty $\mu \mathrm{L}$ Trypsin buffer $(4 \mu \mathrm{g}$ Trypsin in $40 \mu \mathrm{L} 100 \mathrm{mM}$ $\mathrm{NH}_{4} \mathrm{HCO}_{3}$ ) was added, mixed well at $600 \times g$ for $60 \mathrm{~s}$, and placed at $37^{\circ} \mathrm{C}$ for $16-18 \mathrm{~h}$. The collecting tube was replaced and centrifuged at $14000 \times g$ for $15 \mathrm{~min}$. Then, $40 \mu \mathrm{L} 25 \mathrm{mM} \mathrm{NH}_{4} \mathrm{HCO}_{3}$ was added and centrifuged at $14000 \times g$ for $15 \mathrm{~min}$, and the filtrate was collected. The peptides were desalted by $\mathrm{C}_{18}$ cartridge, lyophilized, and redissolved in $40 \mu \mathrm{L} 0.1 \%$ formic acid solution. The peptides were quantified by photometry at $\mathrm{OD}_{280}$.

\section{Mass spectrometry}

A $5 \mu \mathrm{g}$ sample of each group was analyzed in triplicate using LC/MS/ MS. The separation was done using an EASY-nLC HPLC (Thermo Scientific, USA). Flowing phases A was $0.1 \%(\mathrm{v} / \mathrm{v})$ formic acid (Fluka), phases B was acetonitrile solution containing $0.1 \%(\mathrm{v} / \mathrm{v})$ formic acid. MS/MS was performed using a Q-Exactive Mass Spectrometer (Thermo Scientific, USA). The chromatographic column was balanced with $95 \%$ liquid $A$. The samples were loaded by the automatic sampler to the loading column and fractionated by the analytical column at the liquid $A$ flow rate of $300 \mathrm{~nL} / \mathrm{min}$. The mass spectrometer was operated in positive mode using a data-dependent acquisition method. The scanning range of the parent ions was 300-1800 m/z. After each full scan, the 20 most intense precursors were selected for fragmentation. The dynamic exclusion for MS/MS was set as $60 \mathrm{~s}$. The resolution of MS1 was 70,000 for $200 \mathrm{~m} / \mathrm{z}$. MS2 had unit mass resolution.

\section{Bioinformatics analysis}

MaxQuant software was used for database identification and quantitative analysis. The relevant parameters and instructions were as follows: the maximum number of permissible leak-cut sites was 2; the mass tolerance of primary ion and secondary ion plasmid were 6 and 20 ppm, respectively. All databases of the library are uniprot_Escherichia_coli_1124415_20180910.fasta. The quantitative strength values of unique peptide and razor peptide were adopted to carry out protein quantification using the LFQ algorithm. After the proteomic data were analyzed and processed, the screened differential proteins were annotated and attributed to protein function. 


\section{Transcriptional level verification of differentially expressed proteins}

The total RNA extraction method was carried out according to the total RNA extraction kit for biological bacteria (Baitek). Realtime PCR primers were designed for 16 related genes and 16S DNA using Primer 5.0 software. The primers used in qRT-PCR are presented in supplementary materials.

\section{Results}

\section{Contribution of sulto sulfonamide resistance}

MIC tests confirmed that the sulfonamide resistance gene was generated successfully. The sulfonamide resistance gene expressed normally and donated sulfisoxazole resistance to the cells. E. coli BL21: pET23a-sul1, E. coli BL21: pET23a-sul2 and E. coli BL21: pET23a-sul3 had MIC values of $4 \mathrm{mg} / \mathrm{mL}$ for sulfisoxazole.

\section{The fitness cost of sulfonamide resistance genes in Escherichia coli}

The plasmid stability of four genetically engineered strains was analyzed under free selection pressure and sulfisoxazole inhibition concentration. The results showed no plasmid loss in strains E. coli BL21: pET23a-sul1, E. coli BL21: pET23a-sul2 and control strains E. coli BL21: pET23a, but the plasmid loss was $76 \% \pm 4 \%$ after 10 days of subculture. No plasmid loss was observed in the control strain E. coli BL21: PET23a at the subinhibitory concentration (5 \% MIC, $12.5 \mu \mathrm{g} / \mathrm{mL}$ ).

The growth curve of 4 genetically engineered strains was drawn under adequate nutrition and in the absence of drug selection pressure and other influencing factors. E. coli BL21: pET23a-Sul3 showed a reduction in growth ability; however, the other two strains showed no significant difference from the control strain $(P 0.05)$. In the same way, E. coli BL21: PET23a-sul3 had the lowest microbiota diameter and its motor ability was decreased compared with the other three strains $(P<0.05)$. E. coli $\mathrm{BL} 21$ : PET23a-sul1, E. coli BL21: PET23a-sul2 and the control strain E. coli BL21: PET23a showed no significant difference in colony circle diameter $(P 0.05)$. E. coli BL21: PET23A was used as the control, and three pairs of competitive tests were carried out using the method of combining resistance plate screening and PCR verification. An inevitable decrease was observed in adaptability by combining the above experimental results and comparing E. coli BL21: PET23a-sul3 with E. coli BL21: PET23asul1 and E. coli BL21: PET23a-sul2.

\section{Quality control analysis of proteome}

A total of 2446 proteins were identified by uniprot_Escherichia_coli_1124415_20180910 database. The number of proteins identified in 12 samples of 4 groups is shown in the table 1 . The 2446 proteins identified by LC-MS/MS were compared quantitatively by MaxQuant software LFQ algorithm.

\section{Bioinformatics analysis of differentially expressed proteins}

\section{Gene Ontology (GO) functional annotation analysis}

In terms of cell composition, the protein changes were mainly located in the cell membrane and cell-matrix among all six groups. These changes are reflected primarily in catalytic activity and binding functions, which involved cells' metabolic process.

\section{KEGG pathway analysis}

In the paired comparison between the engineered strains carrying sul1, sul2 and control strains, proteins involved in the pathways were relatively concentrated. Apart from the glucose and nucleotide metabolisms, they were also involved in the ABC transporter and the two-component systems. However, in the paired comparison between E. coli BL21: PET23a-sul3 strains in 
the experimental and control groups, the metabolic pathways were relatively dispersed, mainly focused on glucose and nucleotide metabolism pathways.

\section{Analysis of the variation trend of differentially expressed proteins}

In E. coli BL21: pET23a-sul1 and E. coli BL21: pET23a-sul2 strains, proteins fliA, fliC and their upstream transcriptional activator fliZ in the two-component system were significantly upregulated. However, IrhA, the transcriptional inhibitor expressed by type I pili, was significantly downregulated.

The protein SUL1, which is involved in folic acid metabolism, was significantly upregulated in E. coli BL21: pET23a-sul1 strain. Besides, molybtrexate adenosine transferase, molybtrexate synthase catalyzed subunit and cyclopyranxate monophosphate synthase were upregulated by 1.7 and 1.6 times, respectively. 2-amino-4-hydroxy-6-hydroxymethyl dihydroteropterine diphosphate kinase was changed from zero to zero, and 4-amino-4-deoxy branched-acid lythase was altered from existing to non-existing. The protein expression of QueE (7-carboxy-7-deazaguanine synthase), which is involved in the pathway of folic acid metabolism, was downregulated 1.8 times in E. coli BL21: pET23a-sul2 strain. E. coli BL21: pET23a-su/3 strain significantly reduced the number of differential proteins involved in the pathway of folic acid metabolism, and significantly upregulated the expression of dihydrospteric acid synthase SUL3

In this study, obvious differences were observed in the ABC transporter system pathway by KEGG pathway analysis. The expressions of ATP-binding proteins $u g p C$, rbsA and $g s i A$, which are closely related to energy supply, were significantly increased in E. coli BL21: pET23a-sul1 or E. coli BL21: pET23a-sul2, but there was no significant change in E. coli BL21: pET23a-sul3.

Analysis of individual differentially expressed proteins showed that the differential expression ratio of the outer membrane pore protein $o m p D$ was the highest among all the proteins. In E. coli BL21: pET23a-sul3, the quantitative strength of ompDLFQ protein was $1.7 \times 10^{9}$, which was increased by 29.93 times compared with the control strain E. coli BL21: pET23a.

\section{Transcriptional level analysis of differentially expressed proteins}

Genes fliZ, fliA, fliC, IrhA (bacteria movement-related), sul1, sul2, sul3 (folic acid metabolic pathways related), moaB (molybdenum with poison adenosine transferase), moaE (molybdenum with poison synthetase catalytic subunit), moaC (pyran ring poison monosodium phosphate synthetase), APT94_19870 (dihydrogen pteridine diphosphate kinase), C5P43_33360, ugpC, rbsA, gsiA (ATP binding protein related) and ompD (outer membrane channel proteins), and other 16 genes were chosen for Real-time PCR analysis. Based on 16s rDNA internal genes, $2^{-\Delta \Delta C t}$ relative quantitative method was used for comparative quantitative analysis of target genes.

The comparative quantitative analysis results showed that the variation trend of target gene mRNA level expression obtained by real-time PCR analysis was the same as that obtained by Label-free proteomic analysis (Figure 6).

\section{Discussion}

Sulfonamide resistance genes sul1, sul2, and sul3 can mediate high levels of drug resistance of Escherichia coli to sulfonamides. Several studies have demonstrated these three drug resistance genes are widespread in the pork industry [20-23]. This study was to investigate the biological basis of the prevalence and transmission of sulfonamide-resistant genes sul1, sul2 and sul3.

The sulfonamide resistance genetic engineering strains with the same genetic background were constructed by gene cloning and recombination techniques. In recent years, the construction of drug-resistant genes in engineered bacteria has been more and more used to research the fitness cost of drug-resistant genes in strains. Nang et al recombined mobile colistin resistance (mcr-1) on a low-copy and broad-spectrum host range vector pBBR1MCS-5 and switched it to Klebsiella pneumonia B5055 to 
study the fitness cost of $m c r-1$ gene [24]. As expected, drug-resistant genetically engineered bacteria constructed in this study showed high resistance to sulfonamide in MIC tests.

The evolution and persistence of antibiotic resistance in the bacterial population depend on a complex calculus rooted in biological fitness cost associated with the resistance and the impact of the resistance pressure. In the presence of high levels of antibiotics, access to antibiotic resistance mechanisms offers an adaptive advantage over susceptible competitors [25]. However, there are often deleterious effects in the absence of antibiotic resistance mechanisms, typically observed as an increased generation time and reduced survival in a host [19]. These observations suggest that susceptible, higher fitness populations should generally outcompete resistant bacteria after removing selection pressure. However, several factors can cause the stability of this resistance: 1) co-selection of resistance genes with other functions that confer a fitness advantage $[26,27]$; 2) presence of resistances that impose a very low or no cost [28, 29]; 3) compensatory evolution that reduces the fitness cost, often without loss of the resistance [30,31]

Studies have shown that the change of fitness cost will affect normal physiological functions of bacteria to a certain extent, such as growth ability, movement ability, virulence and plasmid stability. In general, there was no significant difference between E. coli BL21: $\mathrm{pET} 23 \mathrm{a}-$ sul1, E. coli BL21: $\mathrm{pET} 23 \mathrm{a}-$ sul2 and control E. coli BL21: $\mathrm{pET} 23 \mathrm{a}(P>0.05)$. E. coli BL21: $\mathrm{pET} 23 \mathrm{a}-$ sul3 showed a significant $(P<0.05)$ decrease in growth capacity, locomotion capacity, and loss of plasmid. E. coli BL21: pET23a-sul3 also showed a certain fitness cost in the in vitro competition test. Sul1 and sul2 had lower fitness cost, which illustrated one of the important reasons for the widespread prevalence of these two genes from the biological basis. Theoretically, suppose the adaptability of specific genotypes of drug-resistant bacteria is lower than the average adaptability of the population. In that case, it will be a disadvantage in competition, and these genotypes may be eliminated gradually. However, it is noteworthy that E. coli BL21: $\mathrm{pET} 23 \mathrm{a}-$ sul3 adaptability was restored in response to sulfonamides selection pressure. Therefore, if the selective pressure of sulfa drugs persists in nature, the prevalence of sul3 gene will gradually increase.

Bacterial proteome changes dynamically with growth environment and growth stage, and there are different protein expression profiles under various conditions. Label-free quantitative proteomics was used to explore the possible fitness mechanisms further.

The two-component system (TCS) is the main pathway for bacteria to complete chemotactic movement [32, 33]. It was found that in E. coli BL21: pET23a-sul1 and E. coli BL21: pET23a-sul2 strains, proteins fliA, flic and their upstream transcriptional activator fliZ were significantly upregulated in the TCS. However, IrhA, a transcriptional inhibitor expressed by type I pili, was significantly down-regulated. The increase of FliZ protein expression can promote the expression of FliA and FliC, increase the synthesis of flagellin, and make the cells gain better motility and improve the cells survival [34, 35]. As a transcriptional regulatory inhibitor of the flagellum, motility and chemotactic gene IrhA can promote type I pili and biofilm formation by inhibiting IrhA [36, 37]. However, there was no significant change in these genes in E. coli BL21: pET23a-sul3, which may be one reason for its lower adaptability than that of sul1 and sul2.

Most prokaryotes must synthesize folate themselves. DHPS is the target enzyme of sulfonamides, which binds to it and inhibits its activity, to reveal antibacterial effects [38]. Sul1, sul2 and sul3 are dhps substitution genes, and their expression products all act as dihydrosphenoate synthase. The function of dihydrosphenoate synthase substitution enzyme exerted by SUL3 may not be sufficient to balance the influence of 2-amino-4-hydroxy-6-hydroxymethyl dihydrosphenoidine diphosphate kinase overexpression. Silent expression of 4-amino-4-deoxybranch acid cleasthase on the folic acid metabolism pathway may affect the synthesis of folic acid and reducing adaptability.

Multidrug efflux transporters are prevalent in the antibiotic resistance mechanisms as they bestow an ability to bacteria to evade most current therapies [39, 40]. ATP-binding cassette transporters are essential biomolecule transport systems in organisms that rely on ATP hydrolysis to obtain energy for transporting various biomolecules [39]. In this study, the energy supply by ATP binding protein UgpC, RbsA, GsiA in E. coli BL21: pET23a-sul1 and E. coli BL21: pET23a - sul2 increased significantly. After obtaining exogenous sul1 and sul2 genes, the strain was subjected to fine regulation by ATP energy supply system in the logarithmic phase. However, there was no noticeable change in E. coliBL21: pET23a -sul3 strains. The changes 
of the $A B C$ transporter system are closely related to the strain's physiological state and growth conditions. Therefore, the association between the $A B C$ transporter system and bacterial adaptability needs to be further verified.

Outer membrane pore protein $\mathrm{OmpD}$ is involved in discharging bacterial metabolic poisons, which are mainly caused by metabolic changes and insufficient bacterial carbon sources. OmpD is overexpressed when metabolism is inhibited, or carbon sources are not sufficient [41]. In this study, the expression of OmpD protein in E. coli BL21: pET23a-sul3 was significantly increased. Thus, it was speculated that $E$. coli BL21: pET23a-sul3 metabolism was inhibited, leading to insufficient carbon source for bacterial metabolism. Accordingly, it was attempted to upregulate $0 \mathrm{mpD}$ to participate in the excretion of toxin in bacterial metabolism, which consumed energy and affected its fitness cost.

\section{Conclusions}

In this study, the compensation mechanism of sulfonamide resistance genes in $E$. coli was explored in constructed engineered bacteria carrying sul1, sul 2 and sul3 genes. The results showed that the fitness cost of sul 3 was significantly higher than sul 1 and sul2 $(P<0.05)$. The sulfonamide resistant genes obtained by bacteria directly affect the folic acid metabolism pathway of $E$. coli. sul1 and sul 2 genes make more differential proteins involved in folic acid synthesis. Meanwhile, ATP-binding proteins such as UgpC, RbsA and GsiA, which are closely related to energy supply, were upregulated, making folic acid synthesis in bacteria more accurately regulated. In addition, the flagella-related proteins FliA and FliC and their upstream transcriptional activator FliZ in the two-component system were significantly upregulated, while the type I pili transcriptional inhibitor LrhA was downregulated so that the bacteria could obtain better motility and maintain their survival. The fitness compensation mechanism of sul3 was relatively weak. The considerably upregulated OmpD of E. coli BL21: pET23a-sul3 indicated that the bacteria's metabolism was inhibited and energy was insufficient, showing a high adaptive cost, leading lower prevalence of sul3 than sul1 and sul2.

\section{Declarations}

\section{Acknowledgements}

Not applicable

\section{Authors' contributions}

Y.Q.Z constructed the engineering strains. Y.Q.Z. performed MICs, plasmid stability, growth kinetics and motility test. J.H.F. performed competition experiments. Y.Q.Z. and J.H.F. performed bioinformatics analysis and transcriptional level verification. D.F.Q. and J.Z.H. supervised the study. Y.Q.Z., D.F.Q. and Z.D. wrote the manuscript. The authors read and approve the final manuscript.

\section{Funding}

Not applicable

\section{Availability of data and materials}

Not applicable

\section{Ethics approval and consent to participate}

Not applicable.

\section{Consent for publication}

Not applicable. 


\section{Competing interests}

The authors declare that they have no competing interests.

\section{Author details}

12Zhejiang Gongshang University, Hangzhou 310035, PR China, 1304406819@qq.com

2 Zhejiang Gongshang University, Hangzhou 310035, PR China, heze0305@qq.com

${ }^{3}$ Zhejiang Gongshang University, Hangzhou 310035, PR China, d.zaeim@zjgsu.edu.cn

\section{References}

1. Shrivastava., S. P, and R. J, World health organization releases global priority list of antibiotic-resistant bacteria to guide research, discovery, and development of new antibiotics. Journal of Medical Society, 2018. 32(1): p. 76.

2. Beheshti-Maal, K., et al., Synthesis of Some Novel Sulfonamide-imines as Potential Antimicrobial Agents. Letters in Organic Chemistry, 2018. 15(2): p. 111-117.

3. Urumova, V., Prevalence of resistance to sulfonamides and streptomycin among commensal porcine Escherichia coli isolates. Revue de Medecine Veterinaire, 2016. 167: p. 38-44.

4. Buwembo, W., et al., Point Mutations in the folP Gene Partly Explain Sulfonamide Resistance of Streptococcus mutans. International Journal of Microbiology, 2013. 367021: p. 1-7.

5. Sanchez-Osuna, M., et al., Origin of the mobile di-hydro-pteroate synthase gene determining sulfonamide resistance in clinical isolates. Frontiers in Microbiology, 2019. 10: p. 1-9.

6. Suzuki, S. and P.T. Hoa, Distribution of quinolones, sulfonamides, tetracyclines in aquatic environment and antibiotic resistance in indochina. Front Microbiol, 2012. 3: p. 67.

7. Hsu, J.-T.a.C., C.-Y.b;Young, C.-W.c;Chao, W.-L.c;Li, M.-H.c;Liu, Y.-H.c;Lin, C.-M.C;Ying, C.C, Prevalence of sulfonamide-resistant bacteria, resistance genes and integron-associated horizontal gene transfer in natural water bodies and soils adjacent to a swine feedlot in northern Taiwan. Journal of Hazardous Materials, 2014. 277: p. 34-43.

8. Huddleston, J.R., Horizontal gene transfer in the human gastrointestinal tract: potential spread of antibiotic resistance genes. Infect Drug Resist, 2014. 7: p. 167-76.

9. Wu, S., et al., Prevalence and characterization of plasmids carrying sulfonamide resistance genes among Escherichia coli from pigs, pig carcasses and human. Acta Vet Scand, 2010. 52: p. 47.

10. Card, R., et al., Virulence Characterisation of Salmonella enterica Isolates of Differing Antimicrobial Resistance Recovered from UK Livestock and Imported Meat Samples. Front Microbiol, 2016. 7: p. 640.

11. Ben, W., et al., Dissemination of antibiotic resistance genes and their potential removal by on-farm treatment processes in nine swine feedlots in Shandong Province, China. Chemosphere, 2017. 167: p. 262-268.

12. Swedberg, G., S. Castensson, and O. Skold, Characterization of Mutationally Altered Dihydropteroate Synthase and Its Ability to Form a Sulfonamide-Containing Dihydrofolate Analog. JOUNMAL OF BACTERIOLOGY, 1979. 79: p. 129-136.

13. Lars Sundstrim, et al., Site-specific recombination promotes linkage_between trimethoprim-and sulfonamide resistance genesSequence characterization of dhfrV and sul and a recombination active locus of Tn21. Mol Gen Genet, 1988. 213: $p$. 191-201.

14. Enne; , V.I., et al., Enhancement of host fitness by the sul2-coding plasmid p9123 in the absence of selective pressure. The Journal of antimicrobial chemotherapy, 2004. 53: p. 958-963.

15. Martin, C., J. Timm, and J. Rauzier, Transposition of an antibiotic resistance element inmycobacteria. Nature, 1990. 345: p. 739-743. 
16. Yiping, T., et al., Occurrence of Quinolone and Sulfonamide Antibiotics in Swine and Cattle Manures from Large-scale Feeding Operations of Guangdong Province. Environmental Sciences 2011. 32ه4ロ: p. 1188-1193.

17. Hua, W., C. Yixuan, and F. Chengran, Occurrence of Veterinary Antibiotics in Swine Manure from Large-scale Feedlots in Zhejiang Province, China. Bulletin of Environmental Contamination \& Toxicology, 2017. 98(4): p. 472-477.

18. Pan, X., et al., Residual veterinary antibiotics in swine manure from concentrated animal feeding operations in Shandong Province, China. Chemosphere, 2011. 84(5).

19. Andersson, D.I. and D. Hughes, Antibiotic resistance and its cost: is it possible to reverse resistance? Nat Rev Microbiol, 2010. 8(4): p. 260-71.

20. Hammerum, A.M., et al., Detection of sul1, sul2 and sul3 in sulphonamide resistant Escherichia coli isolates obtained from healthy humans, pork and pigs in Denmark. Int J Food Microbiol, 2006. 106(2): p. 235-7.

21. Johnson, J., et al., Molecular analysis of Escherichia coli from retail meats (2002-2004) from the United States national antimicrobial resistance monitoring system. Clinical Infectious Diseases, 2009. 49(2): p. 195-201.

22. Vogt, D., et al., Occurrence and Genetic Characteristics of Third-Generation Cephalosporin-Resistant Escherichia coli in Swiss Retail Meat. Microbial Drug Resistance: Mechanism, Epidemiology, \& Disease, 2014. 20(5): p. 485-494.

23. Jiang, H., et al., Diverse Mobile Genetic Elements and Conjugal Transferability of Sulfonamide Resistance Genes (sul1, sul2, and sul3) in Escherichia coli Isolates From Penaeus vannamei and Pork From Large Markets in Zhejiang, China. Frontiers in Microbiology, 2019. 10: p. 1787-1797.

24. Nang, S.C., et al., Fitness cost of mcr-1-mediated polymyxin resistance in Klebsiella pneumoniae. J Antimicrob Chemother, 2018. 73(6): p. 1604-1610.

25. Dan, A., The biological cost of mutational antibiotic resistance: any practical conclusions? Current opinion in microbiology, 2006. 9(5): p. 461-465.

26. Baker-Austin, C., et al., Co-selection of antibiotic and metal resistance. Trends Microbiol, 2006. 14(4): p. $176-82$.

27. Yates, C.M., et al., Enhancement of bacterial competitive fitness by apramycin resistance plasmids from non-pathogenic Escherichia coli. Biology letters, 2006. 2: p. 463-465.

28. Ramadhan, A.A. and E. Hegedus, Survivability of vancomycin resistant enterococci and fitness cost of vancomycin resistance acquisition. J Clin Pathol, 2005. 58(7): p. 744-6.

29. Criswell, D., et al., Mutations conferring aminoglycoside and spectinomycin resistance in Borrelia burgdorferi. Antimicrob Agents Chemother, 2006. 50(2): p. 445-52.

30. Wiesch, P., Compensation of Fitness Costs and Reversibility of Antibiotic Resistance Mutations. . Antimicrobial Agents \& Chemotherapy, 2010. 54(2): p. 2085-92.

31. Andersson, D.I. and D. Hughes, Persistence of antibiotic resistance in bacterial populations. FEMS Microbiol Rev, 2011. 35(5): p. 901-11.

32. Parkinson, J.S. and E.C. Kofoid, Communication modules in bacterial signaling proteins. annual reviews genetic, 1992(26): p. 71-112.

33. Tierney, A.R. and P.N. Rather, Roles of two-component regulatory systems in antibiotic resistance. Future Microbiology, 2019. 14(6): p. 533-552.

34. Jubelin, G., et al., Fliz is a global regulatory protein affecting the expression of flagellar and virulence genes in individual Xenorhabdus nematophila bacterial cells. PLoS Genet, 2013. 9(10): p. e1003915.

35. Xia, Q., et al., Adaptive mechanisms of Campylobacter jejuni to erythromycin treatment. BMC Microbiology 2013. 13: $\mathrm{p}$. 133-149.

36. D. Lehnen, C.B., et al., LrhA as a new transcriptional key regulator of flagella,motility and chemotaxis. Molecular Microbiology, 2002. 45(2): p. 521-523.

37. Blumer, C., et al., Regulation of type 1 fimbriae synthesis and biofilm formation by the transcriptional regulator LrhA of Escherichia coli. Microbiology (Reading), 2005. 151(Pt 10): p. 3287-3298. 
38. Moukhlis, R., et al., Linking Pneumocystis jiroveci sulfamethoxazole resistance to the alleles of the DHPS gene using functional complementation in Saccharomyces cerevisiae. Clin Microbiol Infect, 2010. 16(5): p. 501-7.

39. Orelle, C., K. Mathieu, and J.M. Jault, Multidrug ABC transporters in bacteria. Res Microbiol, 2019. 170(8): p. 381-391.

40. Wasi, M., et al., ABC Transporter Genes Show Upregulated Expression in Drug-Resistant Clinical Isolates of Candida auris: $A$ Genome-Wide Characterization of ATP-Binding Cassette (ABC) Transporter Genes. Frontiers In Microbiology, 2019. 10: p. 1445-1456.

41. Santiviago, C.A., et al., Global regulation of the Salmonella enterica serovar typhimurium major porin, OmpD. J Bacteriol, 2003. 185(19): p. 5901-5.

\section{Tables}

Table 1 The significant differentially expressed proteins in recombinant bacteria 


\begin{tabular}{|c|c|c|c|c|c|c|c|c|}
\hline \multirow[t]{2}{*}{ Protein Name } & \multirow{2}{*}{$\begin{array}{l}\text { Pathway or } \\
\text { Function. }\end{array}$} & \multicolumn{4}{|c|}{ Quantitative results of LFQ protein } & \multicolumn{3}{|c|}{ Differential expression ${ }^{a}$} \\
\hline & & $a$ & S1 & s2 & s3 & $\mathrm{S} 1 / \mathrm{a}$ & s2/a & s3/a \\
\hline SUL 1 & $\begin{array}{l}\text { Folate } \\
\text { biosynthesis }\end{array}$ & $8.50 \mathrm{E}+05$ & $1.01 \mathrm{E}+11$ & / & / & $1.18 \mathrm{E}+05^{\star}$ & / & l \\
\hline SUL2 & $\begin{array}{l}\text { Folate } \\
\text { biosynthesis }\end{array}$ & $4.52 E+07$ & I & $7.47 \mathrm{E}+09$ & I & I & ${ }_{\star}^{165.15}$ & l \\
\hline SUL3 & $\begin{array}{l}\text { Folate } \\
\text { biosynthesis }\end{array}$ & $1.18 \mathrm{E}+05$ & / & / & $2.85 E+10$ & / & / & $2.41 \mathrm{E}+05$ \\
\hline Fliz & $\begin{array}{l}\text { Bacterial } \\
\text { motility }\end{array}$ & $1.18 \mathrm{E}+09$ & $1.74 \mathrm{E}+09$ & $1.85 \mathrm{E}+09$ & $1.20 \mathrm{E}+09$ & 1.47 * & 1.56 * & 1.02 \\
\hline FliA & $\begin{array}{l}\text { Bacterial } \\
\text { motility }\end{array}$ & $2.52 E+07$ & $4.52 \mathrm{E}+07$ & $4.93 \mathrm{E}+07$ & $2.44 \mathrm{E}+07$ & 1.79 * & 1.96 * & 0.97 \\
\hline FliC & $\begin{array}{l}\text { Bacterial } \\
\text { motility }\end{array}$ & $1.63 \mathrm{E}+08$ & $6.83 \mathrm{E}+08$ & $3.47 \mathrm{E}+08$ & $1.60 \mathrm{E}+08$ & 4.19 * & 2.13 * & 0.98 \\
\hline LIrhA & $\begin{array}{l}\text { Bacterial } \\
\text { motility }\end{array}$ & $1.90 \mathrm{E}+08$ & $1.81 \mathrm{E}+07$ & $4.81 \mathrm{E}+07$ & $1.69 \mathrm{E}+08$ & 0.10 * & 0.25 * & 0.89 \\
\hline MoaB & $\begin{array}{l}\text { Folate } \\
\text { biosynthesis }\end{array}$ & $1.16 \mathrm{E}+09$ & $1.96 \mathrm{E}+09$ & $2.51 E+09$ & / & 1.68 * & 2.16 * & l \\
\hline MoaE & $\begin{array}{l}\text { Folate } \\
\text { biosynthesis }\end{array}$ & $1.77 \mathrm{E}+08$ & $2.88 \mathrm{E}+08$ & $3.71 \mathrm{E}+08$ & $2.70 \mathrm{E}+08$ & 1.62 * & 2.10 * & $1.52^{\star}$ \\
\hline MoaC & $\begin{array}{l}\text { Folate } \\
\text { biosynthesis }\end{array}$ & $3.33 \mathrm{E}+08$ & $5.27 \mathrm{E}+08$ & $5.54 \mathrm{E}+08$ & / & 1.58 * & 1.66 * & l \\
\hline APT94_19870 & $\begin{array}{l}\text { Folate } \\
\text { biosynthesis }\end{array}$ & / & $2.16 \mathrm{E}+07$ & $2.04 \mathrm{E}+07$ & I & I & / & l \\
\hline C5P43_33360 & $\begin{array}{l}\text { Folate } \\
\text { biosynthesis }\end{array}$ & $2.42 \mathrm{E}+07$ & / & / & I & I & / & I \\
\hline UgpC & $\begin{array}{l}\mathrm{ABC} \\
\text { transporter } \\
\text { system }\end{array}$ & $2.60 \mathrm{E}+07$ & $5.48 \mathrm{E}+07$ & $3.92 \mathrm{E}+07$ & $3.36 \mathrm{E}+07$ & 2.11 * & 1.51 * & 1.29 \\
\hline RbsA & $\begin{array}{l}\text { ABC } \\
\text { transporter } \\
\text { system }\end{array}$ & $5.10 \mathrm{E}+06$ & $1.32 \mathrm{E}+07$ & $1.12 \mathrm{E}+07$ & $5.14 \mathrm{E}+06$ & 2.60 * & 2.20 * & 1.01 \\
\hline GsiA & $\begin{array}{l}\text { ABC } \\
\text { transporter } \\
\text { system }\end{array}$ & $4.43 E+07$ & $6.83 \mathrm{E}+07$ & $7.18 \mathrm{E}+07$ & $4.38 \mathrm{E}+07$ & 1.54 * & 1.62 * & 0.99 \\
\hline OmpD & $\begin{array}{l}\text { Outer } \\
\text { membrane } \\
\text { pore protein }\end{array}$ & $5.61 \mathrm{E}+07$ & $1.08 \mathrm{E}+08$ & $1.02 \mathrm{E}+08$ & $1.68 \mathrm{E}+09$ & 1.92 * & 1.81 * & $29.93^{\star}$ \\
\hline
\end{tabular}

Abbreviation: > 1 represents up-regulation, < 1 represents down-regulation; * represents significant difference.

\section{Figures}



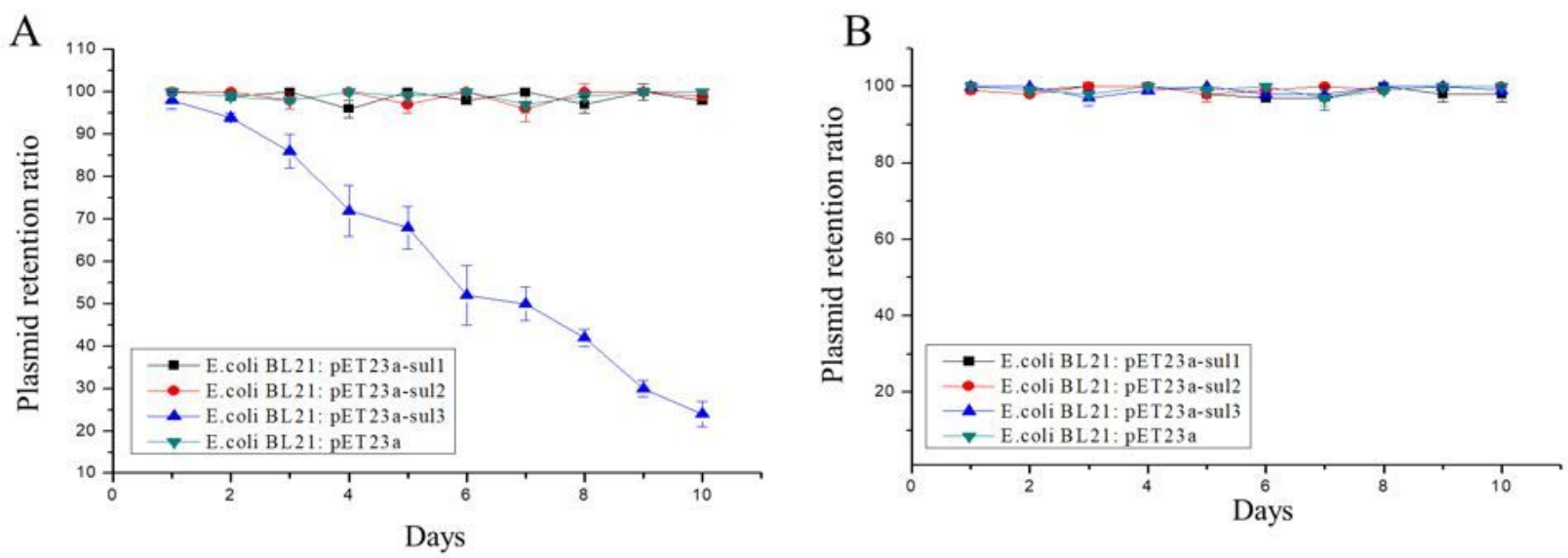

Figure 1

stability of the vector in the gene engineering strains. (A) Results of plasmid stability test without sulfamethoxazole selection pressure; (B)Results of plasmid stability test under the subinhibitory concentration ( $5 \% \mathrm{MIC}, 12.5 \mu \mathrm{g} / \mathrm{mL})$ of control strain $\mathrm{E}$. coli BL21: PET23a.

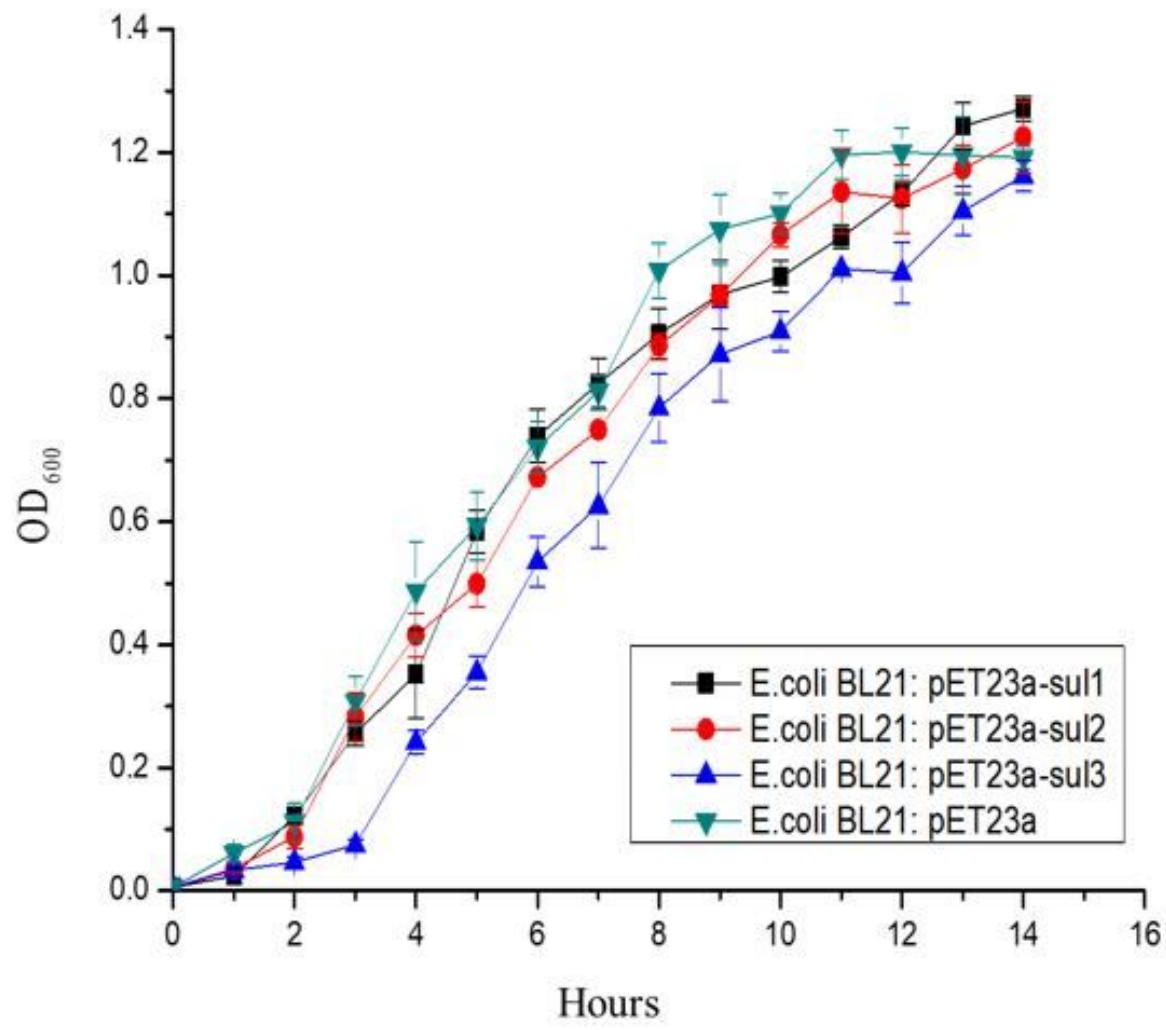

Figure 2

The growth curve of 4 strains of genetically engineered bacteria under the condition of adequate nutrition, no drug selection pressure and no other influencing factors 

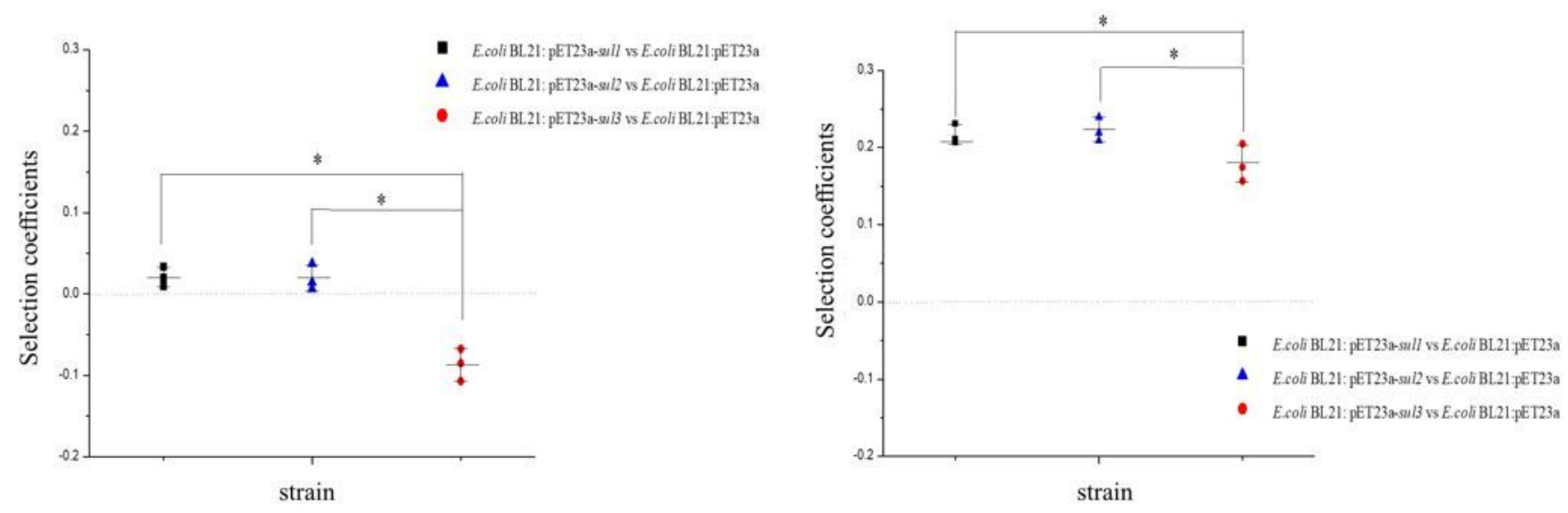

\section{Figure 3}

Selection coefficients for the gene engineering strains against the control strain. (A) Selection coefficient without sulfonamide drug selection pressure; (B) Selection coefficient of control strain E. coli BL21: PET23a under subinhibition concentration

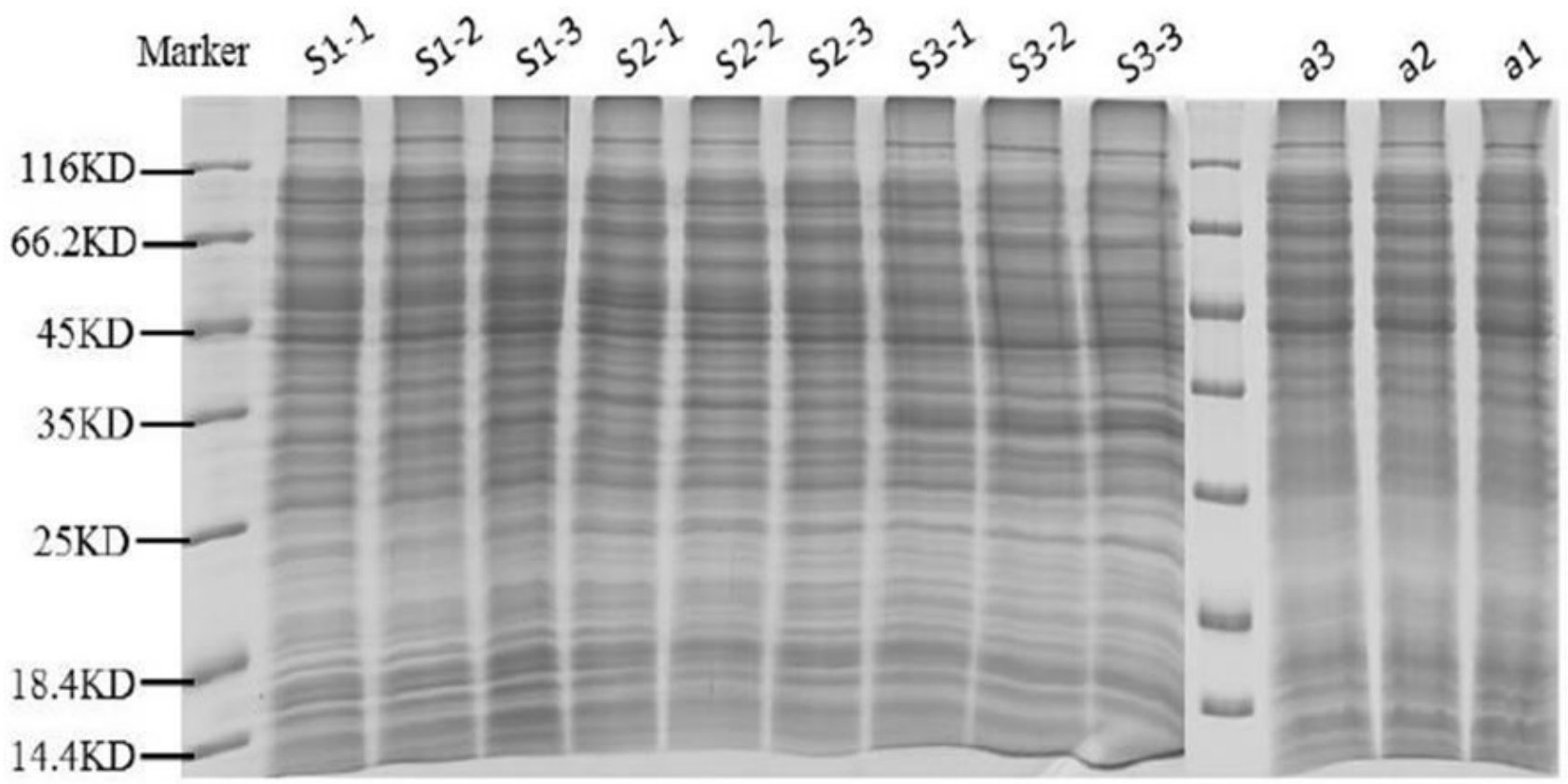

\section{Figure 4}

SDS-PAGE electrophoresis of total protein. a1, a2 and a3 represent three biologically repeated total proteins of strain E. coli BL21: PET23a. S1-1, S1-2 and S1-3 represented total protein of three biologically repeated strains of E. coli BL21:pET23a-sul1; S2-1, S2-2 and S2-3 represented the total protein of three biologically repeated strains of E. coli BL21: pET23a-Sul2; S3-1, S3-2 and S3-3 represent three biologically repeated total proteins of strain E. coli BL21: pET23a-Sul3. 


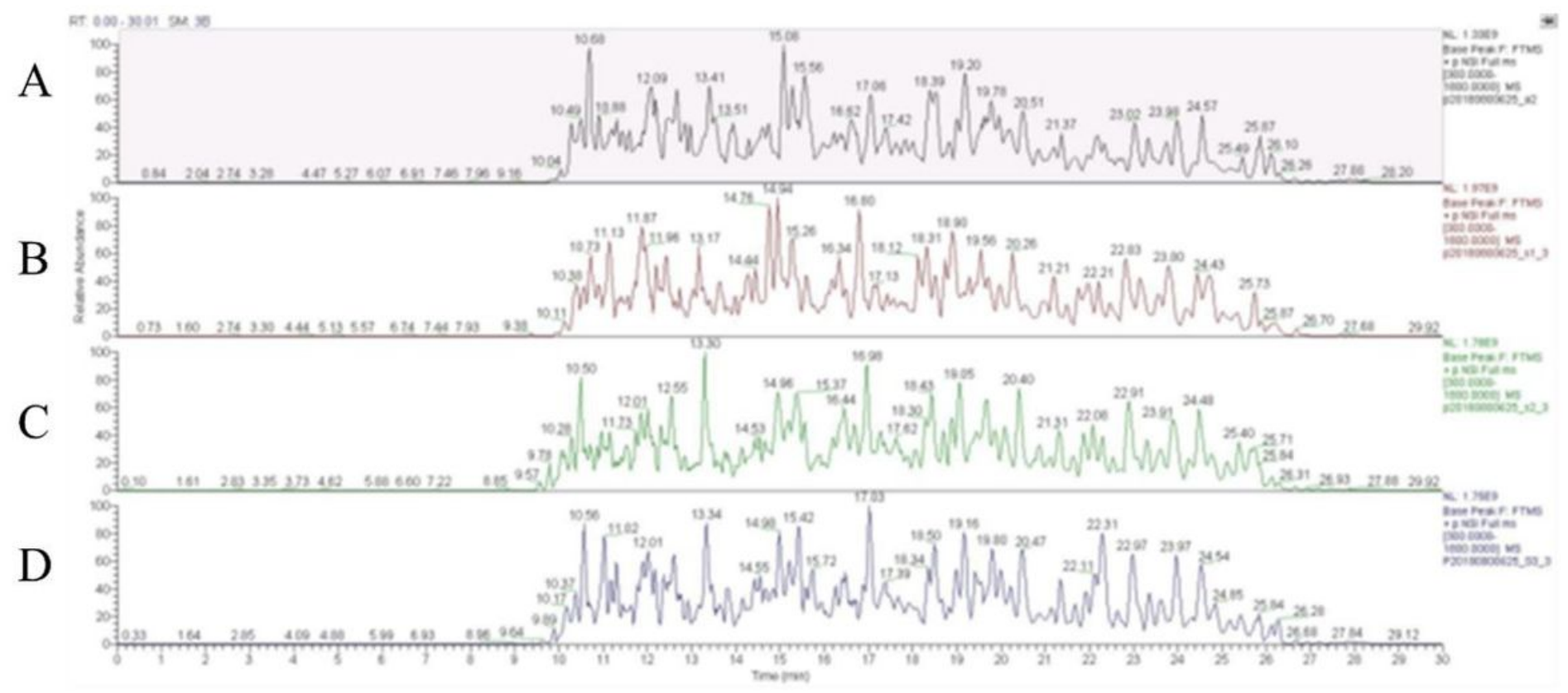

\section{Figure 5}

Basepeak spectrogram analysis of Q-Exactive mass spectrometry. (A) E. coli BL21: pET23a; (B) E. coli BL21:pET23a-sul1;(C) E. coli BL21: pET23a-sul2; (D) E. coli BL21: pET23a-sul3 

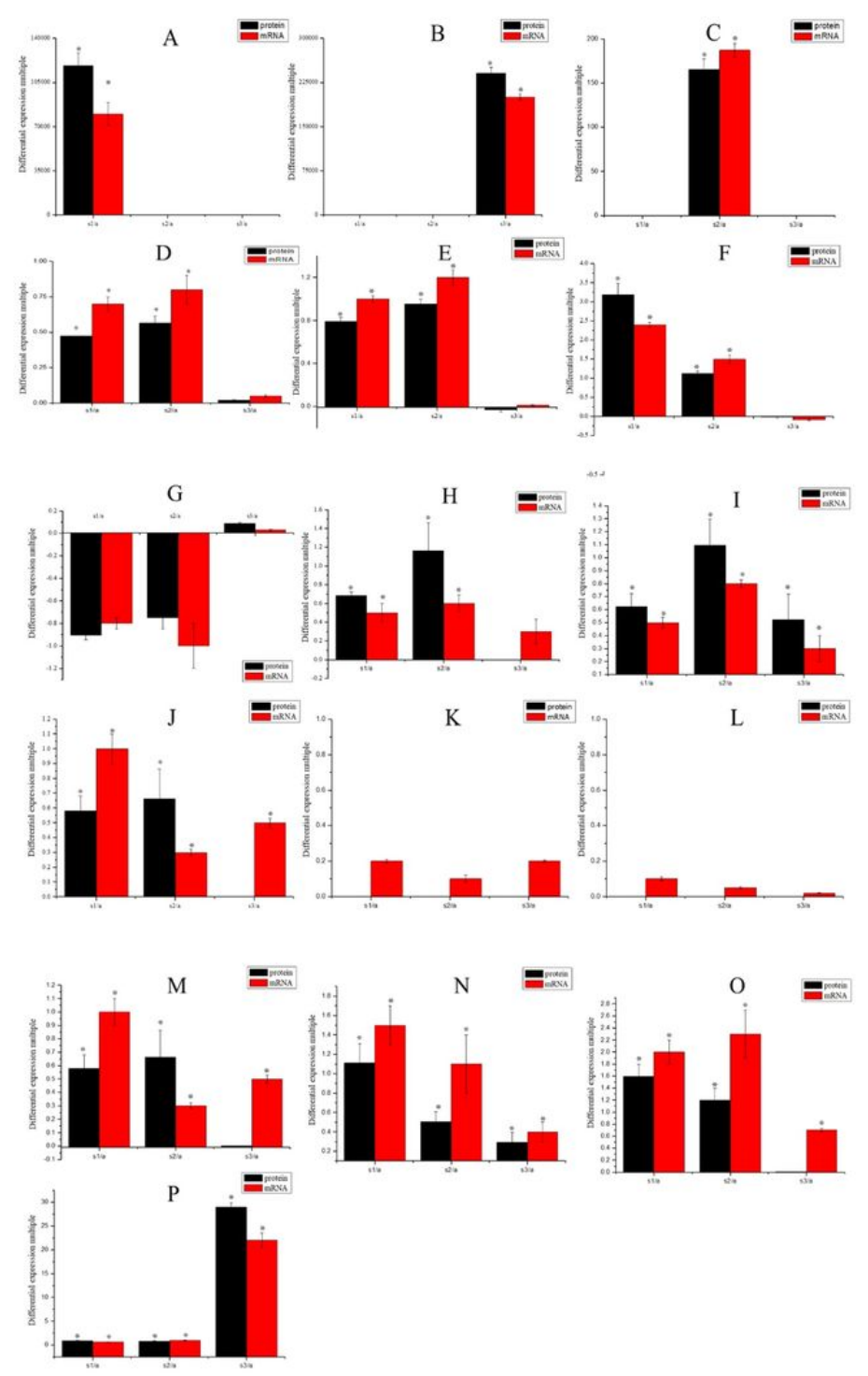

Figure 6

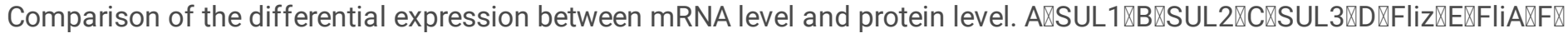

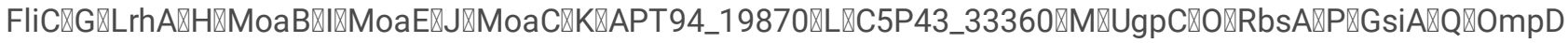

